\title{
Ultrathin Sicopion Composite Cation-Exchange Membranes: Characteristics and Electrodialytic Performance following a Conditioning Procedure
}

\author{
Erik Ayala-Bribiesca, ${ }^{1}$ Mario Boucher, ${ }^{2}$ and Laurent Bazinet ${ }^{1}$ \\ ${ }^{1}$ Dairy Science and Technology Group (STELA), Institute of Nutraceuticals and Functional Foods (INAF) and \\ Department of Food Sciences and Nutrition, Pavillon Paul Comtois, Laval University, Sainte-Foy, QC, Canada G1V $0 A 6$ \\ ${ }^{2}$ SiM Composites, 4925 Rue Lionel Groulx, Bureau 11, Saint-Augustin-de-Desmaures, QC, Canada G3A 1V1
}

Correspondence should be addressed to Laurent Bazinet, laurent.bazinet@fsaa.ulaval.ca

Received 20 October 2011; Accepted 18 January 2012

Academic Editor: Tongwen Xu

Copyright (C) 2012 Erik Ayala-Bribiesca et al. This is an open access article distributed under the Creative Commons Attribution License, which permits unrestricted use, distribution, and reproduction in any medium, provided the original work is properly cited.

\begin{abstract}
The aim of this work was to investigate the properties of Sicopion membranes: an ultrathin $(\approx 20 \mu \mathrm{m})$ composite cationexchange membrane (CEM) made from sulphonated poly(ether-ether-ketone) (SPEEK) containing different levels of sulphonicfunctionalized silica particles (SFSPs). Sicopion membranes were conditioned according to the French Normalization Association procedure, consisting in a series of acid and alkaline washes, and their electrodialytic characteristics were compared to an existent commercial food-grade membrane (CMX-SB). Electrical conductivity of Sicopion membranes was higher than that of CMX-SB membranes (9.92 versus $6.98 \mathrm{mS} / \mathrm{cm}$ ), as well as their water content (34.0 versus 27.6\%). As the SFSP level was reduced, the ionexchange capacity (IEC) of Sicopion membranes increased. Concerning their electrodialytic performances, Sicopion membranes presented a lower demineralization rate than CMX-SB membranes (35.9 versus $45.5 \%$ ), due to an $\mathrm{OH}^{-}$leakage through the pores created by dislodging the SFSP particles during the conditioning procedure.
\end{abstract}

\section{Introduction}

Sicopion is a novel type of membranes made of a composite material combining sulphonic-functionalized silica particles (SFSP) and sulphonated poly(ether-ether-ketone) (SPEEK). In this composite material, the functionalization of silica particles is accomplished by covalently grafting sulphonic acid groups [1]. In the case of SPEEK, concentrated $\mathrm{H}_{2} \mathrm{SO}_{4}$ is used to sulphonate, also by covalent bonding, an aromatic chain of poly(ether-ether-ketone) (PEEK) $[1,2]$. Once the organic and the inorganic phases prepared, they are mixed in specific proportions according to the application requirements. The resulting composite material is then prepared in a membrane form. Among the factors affecting the membrane properties there is the sulphonation degree of the components and the type and amount of SFSP used. A PEEK should be partially sulphonated to decrease its hydrophobicity and produce an ion-exchanging material, but high degrees of sulphonation are to be avoided, since the polymer would then become water soluble, which is the case of $100 \%$ SPEEK $[1,2]$. The amount of SFSPs, as well as their size, determines the formation of a continuous hydrophilic phase and the mechanical properties of the material. A high content of inorganic particles (i.e., SFSP) produces higher membrane hydration and water retention capacity but, in contrast, yields a brittle membrane with lower tear resistance [1].

These materials impart to the membrane a highly functional ion-exchanging structure without inert fillers. At the same time, SFSPs enhance water retention, avoiding membrane dehydration, which has been reported to be a critical factor in cation-exchange membrane (CEM) performance in fuel cell applications [3], for which the membranes were originally designed. In food applications, dehydration of electrodialysis (ED) membranes has been linked to fouling formation on CEM membranes [4]. Hence, interest in Sicopion membranes for food applications lies on the fact they could minimize fouling caused by membrane dehydration. Another potential advantage of Sicopion membranes is their 
thickness, which can be customized to very low values (i.e., under $30 \mu \mathrm{m}$, against $165 \mu \mathrm{m}$ for existing food grade CMXSB membranes) with minimal compromise on mechanical resistance during the ED process. Since less material is used for membrane manufacture, there is an important reduction in material consumption, implying an attractive cost benchmarking with respect to other commercially available membranes.

This study was part of a broader research project aimed at the evaluation of the feasibility of existent electromembrane processes with an ultrathin membrane, as well as the development of new applications of Sicopion membranes for conventional and bipolar membrane electrodialysis of food and nutraceutical products. The aim of this work was to study the characteristics and electrodialytic performance of Sicopion membranes with different SFSP levels that have been conditioned according to the standard NF X 45-200 French Normalization Association procedure [5] for ionexchange membranes. The conditioning procedure is a standard acid/alkaline wash applied to IEM to remove any manufacture residue prior to their study and is of interest for food applications requiring cleaning-in-place (CIP) cycles, where membranes would be required to withstand similar $\mathrm{pH}$ conditions [6].

\section{Experimental}

2.1. Material. Three different Sicopion membranes (SiM Composites, Quebec, QC, Canada) with different levels of sulphonic-functionalized silica particles (SFSPs) with an average diameter of $5 \mu \mathrm{m}(16.7,25.0$, and $35.0 \%$ of SFSP, production lots 0052, 0053, and 0054, resp.) embedded within the SPEEK backbone and one Neosepta CMX-SB cation-exchange membrane (Tokuyama Soda Ltd., Tokyo, Japan) were tested to demineralize a model salt and protein diluate solution. Anion-exchange membranes were, in all cases, Neosepta AMX-SB membranes (Tokuyama Soda Ltd.).

$\mathrm{CaCl}_{2} \cdot 2 \mathrm{H}_{2} \mathrm{O}$ and $\mathrm{KCl}$ were obtained from MAT Laboratory (Quebec, QC, Canada). $\mathrm{NaOH} 1.0 \mathrm{~N}$ and $\mathrm{HCl} 1.0 \mathrm{~N}$ were obtained from Fisher Scientific (Nepean, ON, Canada). $\mathrm{NaCl}$ and $\mathrm{Na}_{2} \mathrm{CO}_{3}$ were obtained from EMD (EMD Chemicals, Gibbstown, NJ, USA). BiPRO whey protein isolate (WPI) was obtained from Davisco Foods International (Eden Prairie, MN, USA). The average concentration of protein $(92.7 \mathrm{~g})$, moisture $(5.0 \mathrm{~g})$, sodium $(600.0 \mathrm{mg})$, potassium (120.0 mg), calcium (120.0 mg), phosphorous $(25.0 \mathrm{mg}$ ), and magnesium $(15.0 \mathrm{mg})$, expressed per $100 \mathrm{~g}$ of BiPRO WPI, as is, was obtained from the manufacturer (Davisco Foods International).

2.2. Electrodialysis Cell. The electrodialysis cell was a microflow-type cell (ElectroCell AB, Täby, Sweden). The stack was mounted with one Neosepta CMX-SB cation-exchange membrane separating the anode rinsing compartment from the concentrate, followed by one Neosepta AMX-SB anionexchange membrane and the tested CEM (Sicopion or CMXSB) defining the diluate compartment. A last Neosepta AMX-SB separated the electrode rinsing solution at the cathode end. This way, the stack defined three closed loops,

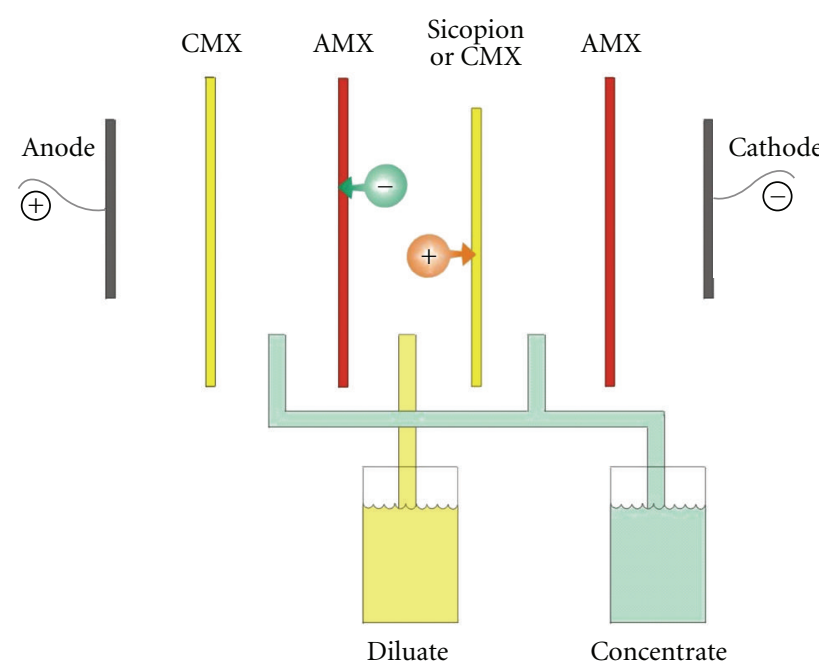

FIGURE 1: Configuration of the electrodialysis (ED) cell used for demineralization of solutions. CMX: CMX-SB cation-exchange membrane, AMX: AMX-SB anion-exchange membrane, (+) demineralizing cations, $(-)$ demineralizing anions. The electroderinsing solution circuit is not shown. Adapted from [7].

as described in previous works [7]. Each closed loop was connected to a separate external plastic reservoir, allowing continuous recirculation (Figure 1). The membranes tested, with an effective surface of $10 \mathrm{~cm}^{2}$, were both in contact with the model salt and protein solution (i.e., diluate) on one side and with the $\mathrm{KCl}$ solution (i.e., concentrate) on the other side.

2.3. Conditioning Procedure. All cation-exchange membranes were conditioned according to the NF X 45-200 procedure of the French Normalization Association (AFNOR) for IEM, Section 5.2.4.1 [5]. Anion-exchange membranes were not conditioned.

Membranes were conditioned as follows.

(a) Immersed in $0.1 \mathrm{M} \mathrm{HCl}\left(100 \mathrm{~mL} / 10 \mathrm{~cm}^{2}\right.$ membrane $)$ for 1 hour.

(b) Rapidly rinsed by immersion in distilled water $\left(250 \mathrm{~mL} / 10 \mathrm{~cm}^{2} \mathrm{membrane}\right)$ and pat-dried with filter paper.

(c) Immersed in $0.1 \mathrm{M} \mathrm{NaOH}\left(100 \mathrm{~mL} / 10 \mathrm{~cm}^{2}\right.$ membrane) for 1 hour.

(d) Rapidly rinsed by immersion in $0.1 \mathrm{M} \mathrm{NaCl}(250 \mathrm{~mL} /$ $10 \mathrm{~cm}^{2}$ membrane).

(e) The cycle was repeated and the membranes kept in $0.1 \mathrm{M} \mathrm{NaCl}\left(100 \mathrm{~mL} / 10 \mathrm{~cm}^{2}\right.$ membrane $)$ until used for membrane analysis and ED procedure.

2.4. Protocol. Once the conditioning procedure completed, membrane characteristics were measured on unused membranes for further comparison with those used for the demineralization procedure. The limiting current density (LCD) value for each ED stack was determined according to the method described by Cowan and Brown [8], obtaining 


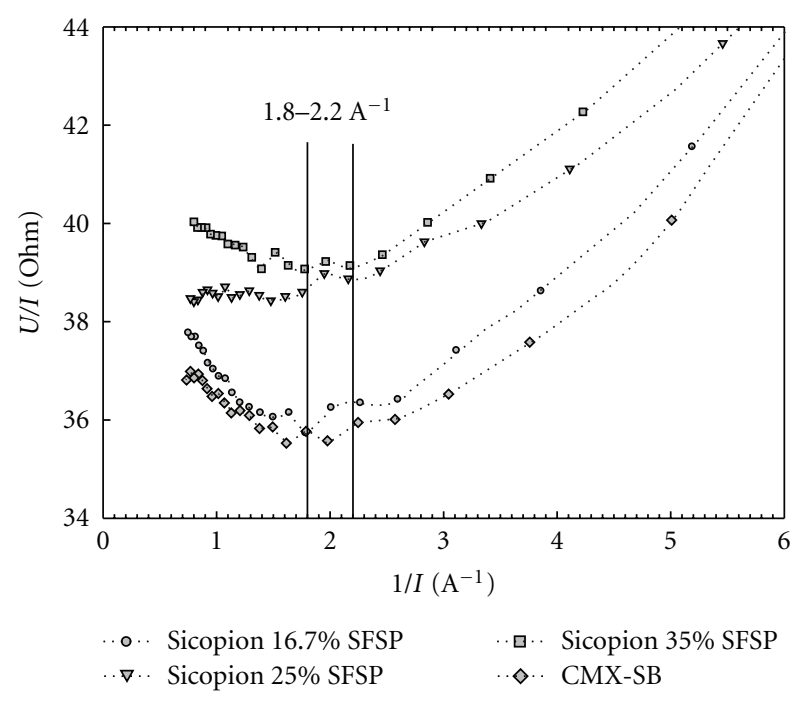

FIgURe 2: Limiting current density (LCD) value determination. Slope changes were found at $0.5 \pm 0.05 \mathrm{~A}$ (i.e., within the 1.8 and $2.2 \mathrm{~A}^{-1}$ range), equivalent to a $\mathrm{LCD}$ value of $50 \mathrm{~mA} / \mathrm{cm}^{2}$ of membrane.

an overall LCD value of $50 \pm 5 \mathrm{~mA} / \mathrm{cm}^{2}$ for all membranes (Figure 2). According to this, and to assure a demineralization process under the LCD value, a current density of $13 \mathrm{~mA} / \mathrm{cm}^{2}$ was fixed on the power supply (model HPD 605SX, Xantrex, Burnaby, BC, Canada) and remained constant during the demineralization procedure. follows.

Solutions used for the demineralization process were as

(a) Model salt and protein solution (i.e., diluate): $1000 \mathrm{mg} / \mathrm{L} \mathrm{Na}_{2} \mathrm{CO}_{3}, 800 \mathrm{mg} / \mathrm{L} \mathrm{KCl}, 800 \mathrm{mg} / \mathrm{L} \mathrm{CaCl}_{2}$, $32.0 \mathrm{~g}$ BiPRO adjusted to $\mathrm{pH} 6.5$ with $\mathrm{HCl} 1.0 \mathrm{~N}$ and refrigerated overnight to ensure proper hydration of proteins.

(b) $\mathrm{KCl}$ solution (i.e., concentrate): $2 \mathrm{~g} / \mathrm{L} \mathrm{KCl}$, adjusted to pH 12 with $\mathrm{NaOH} 1.0 \mathrm{~N}$.

(c) Electrode rinsing solution: $20 \mathrm{~g} / \mathrm{L} \mathrm{NaCl}$.

Electrodialysis was carried out during 100 minutes. Flow rates were adjusted at $900 \mathrm{~mL} / \mathrm{min}$ for the electrode rinsing solution and at $600 \mathrm{~mL} / \mathrm{min}$ for the diluate and concentrate solutions. $2 \mathrm{~mL}$ samples of diluate and concentrate solutions were taken at the beginning and at 20-minute intervals and kept frozen until analyzed by inductively coupled plasma (ICP). Three different membranes of each type were used for each demineralization (triplicate), and a fourth one was kept as a control reference. After the demineralization procedure, the ED stack was dismounted and the CEM were stored in a $0.5 \mathrm{M} \mathrm{NaCl}$ solution until further analysis. Once membrane characteristics determined, the membranes were photographed with a binocular microscope equipped with a digital camera. Finally, membrane samples were ashed, and ICP analyses were done to determine their mineral composition.

\subsection{Analysis Methods}

\subsubsection{Membrane Parameters and Analyses}

Membrane Thickness. Membrane thickness was measured using a Mitutoyo Corp. IDC-type digimatic indicator with absolute encoder (Model ID-C112 EB, Kanagawa-Ken, Japan). The indicator was equipped with a $7 \mathrm{~mm}$ diameter flat contact point. The membrane thickness value was averaged from ten measurements at different locations on the effective surface region of the membrane. Measurements were taken on unused conditioned membranes and on used membranes 24 hours after the ED process.

Membrane Electrical Conductivity. The membrane electrical conductivity was calculated from membrane thickness and its electrical resistance, obtained from membrane conductance. The conductance was measured after a 24-hour immersion of the membranes in a $0.5 \mathrm{M} \mathrm{NaCl}$ solution, which served as the respective reference solution. The method was carried out using a specially designed conductivity clip (Laboratoire des Matériaux Echangeurs d'Ions, Créteil, France) and a YSI conductivity meter (Model 35, Yellow Springs Instrument Co., Yellow Springs, OH, USA). Conductivity was calculated as described in previous studies [4].

Membrane Ion-Exchange Capacity (IEC). IEC of unused conditioned CEM was determined using $\mathrm{Na}^{+}$as counterion, according to the AFNOR procedure for IEM [5]. In the case of Sicopion membranes, given their low mass/surface ratio, the protocol was modified by increasing the defined membrane surface from 10 to $30 \mathrm{~cm}^{2}$, in order to have a meaningful sample.

Water Content. Water content of unused conditioned membranes was determined according to the AFNOR procedure for IEM [5].

Dimensional Stability. The dimensional stability of unused conditioned membranes in acidic and alkaline media was determined according to the official procedure of the AFNOR for IEM [5]. Complementary to this analysis, and prior to conditioning, membrane was marked and measured (i.e., according to the AFNOR procedure [5]) in dry conditions, as obtained from the manufacturer. Afterwards, this value was compared to that of the conditioned membrane to obtain a dry-to-wet dimensional stability coefficient.

Optical Microscopy. Photographs of unused and used membranes were taken at $\times 40$ and $\times 100$ magnitude on a binocular microscope (Laborlux S, Ernst Leitz Wetzlar GmbH, Wetzlar, Germany) equipped with a colour video camera (model hyper HAD, CCD-IRIS/RGB, Sony, Toronto, ON, Canada). The images were processed with Matrox Inspector software (version 3.1, Matrox Electronics Systems Ltd, Dorval, QC, Canada).

Scanning Electron Microscopy and X-Ray EDS. In order to better understand Sicopion membrane characteristics and electrodialytic performance, SEM images of the membranes 
were acquired to verify whether a fouling deposit was present or not. Scanning electron micrographs (SEMs) of uncoated Sicopion membranes used for the ED procedure were acquired at various magnifications levels at $20 \mathrm{kV}$ with a scanning electron microscope (S-3000 N, Hitachi, Japan). Surface elemental analysis of one Sicopion membrane prepared with $16.7 \%$ of SFSP and used for an ED demineralization was performed on an X-ray energy-dispersive spectrometer (EDS) (INCA, Oxford Link Isis, Oxford Instruments, Concord, MA, USA). The EDS conditions were $20 \mathrm{kV}$ accelerating voltage and $14.7 \mathrm{~mm}$ working distance. Elements of interest were silicon, potassium, sodium, phosphorous, sulfur, calcium, chlorine, oxygen, and carbon.

Membrane Ash Determination and Analysis. Samples for ash determination were prepared from $5 \mathrm{~cm}^{2}$ of membrane ashed at $650^{\circ} \mathrm{C}$ for 16 hours in a muffle furnace. Analysis of membrane ashes for silicon quantification was performed by inductive coupled plasma optical emission spectroscopy (ICP-OES) (Optima 4300, Dual View, Perkin-Elmer, Shelton, CT, USA), in axial view at wavelengths 251.611, 212.412, and $288.158 \mathrm{~nm}$.

\subsubsection{Electrodialytic Parameters and Ion Migration}

$p H$ Variation of the Diluate and Concentrate Solutions. The $\mathrm{pH}$ of the diluate and concentrate solutions was measured along the ED process with a $\mathrm{pH}$ meter model SP20 (epoxy gel combination $\mathrm{pH}$ electrode, VWR Symphony), manufactured by Thermo Orion (West Chester, PA, USA).

Conductivity Variation of the Diluate and Concentrate Solutions. Conductivity of the diluate and concentrate solutions was measured along the ED process with an YSI conductivity instrument (model 3100-115V, YSI Inc., Yellow Springs, OH, USA) equipped with an automatic temperature compensation (ATC) immersion probe (model $3252, k=1 / \mathrm{cm}$, YSI Inc.).

Cation Migration. The $2 \mathrm{~mL}$ samples taken during the demineralization procedure were used for cation migration determination. Samples were diluted with HPLC-grade water. Potassium, sodium, and calcium concentrations were determined by ICP (ICP-OES, Optima 4300, Dual View, Perkin-Elmer, Shelton, CT, USA). Analysis was carried-out in radial view. The wavelengths used to determine each element were $766.490,589.592$, and $317.933 \mathrm{~nm}$, respectively.

System Resistance. The system resistance was calculated, using Ohm's Law, from the voltage read directly from the indicators on the power supply and the current intensity read from a digital multimeter (52-0060-2, Mastercraft, Toronto, ON, Canada).

Energy Consumption. In order to compare membrane performance during ED treatment, the total energy consumption was calculated by integrating the voltage as a function of the time multiplied by the current, according to [9]

$$
E=\int_{0}^{100} \frac{U \cdot I}{60} d t
$$

where $E$ is the energy consumption in Watt-hour (Wh), $U$ is the potential (volt), $I$ is the current intensity (ampere), and time is expressed in minutes.

\section{Results and Discussion}

\subsection{Membrane Parameters and Analysis}

3.1.1. Membrane Thickness. Unused conditioned Sicopion membranes were of similar thickness, with a slight decrease as SFSP level increased $(22.7 \pm 0.5,21.3 \pm 0.5$, and $20.7 \pm$ $0.5 \mu \mathrm{m}$, resp. for 16.7, 25.0, and $35.0 \%$ SFSP) (Figure 3). The thickness values obtained for Sicopion membranes were within the specification range established by the manufacturer. These values were, as expected, lower than those obtained for CMX-SB membranes $(165.5 \pm 0.2 \mu \mathrm{m})$, but differences at this level were not subject to comparison, since the different nature of the membranes excludes the necessity for further explanation. Once the ED procedure was finished and the stack was dismounted, membranes (i.e., Sicopion and CMX-SB) were slightly deformed. This deformation was caused by a pressure difference forcing the membrane against spacer in the concentrate compartment. On the other hand, such deformation was not permanent, since membranes recovered their smooth and level surface after being kept 24 hours in a $0.5 \mathrm{~N} \mathrm{NaCl}$ bath. To verify whether a fouling deposit was present or not, thickness was then measured and compared by Students $t$-tests against the corresponding unused membrane. No significant differences were found, and all results supported the absence of any detectable fouling deposit on the membrane surface.

3.1.2. Membrane Electrical Conductivity. Membrane electrical conductivity of unused conditioned Sicopion membranes was similar for all SFSP levels $(9.92 \pm 0.19 \mathrm{mS} / \mathrm{cm})$ and higher than unused CMX-SB membranes $(6.98 \pm 0.24 \mathrm{mS} / \mathrm{cm})$. This difference would be given by the functionalized materials composing Sicopion membranes, having less inert materials in the membrane. 24 hours after the ED treatment, membranes maintained their original conductivity, as compared by Students $t$-tests against the corresponding unused membrane, except for Sicopion membrane with $25.0 \%$ of SFSP $(P=0.026)$, with a $3.28 \pm 1.94 \mathrm{mS} / \mathrm{cm}$ drop (Figure 4$)$. These results indicate that the membrane integrity was not lost during the demineralization. In the case of Sicopion with $25 \%$ SFSP, the difference could be due to the slight thickness reduction, coupled to a minimal but also significant increase in its electrical resistance versus the original value $(P=$ 0.019 , using a Students $t$-test) (Figure 5), since no fouling was visible on such membrane. Nonetheless, such reduced value was still as good as that obtained for CMX-SB membranes after the ED procedures. 


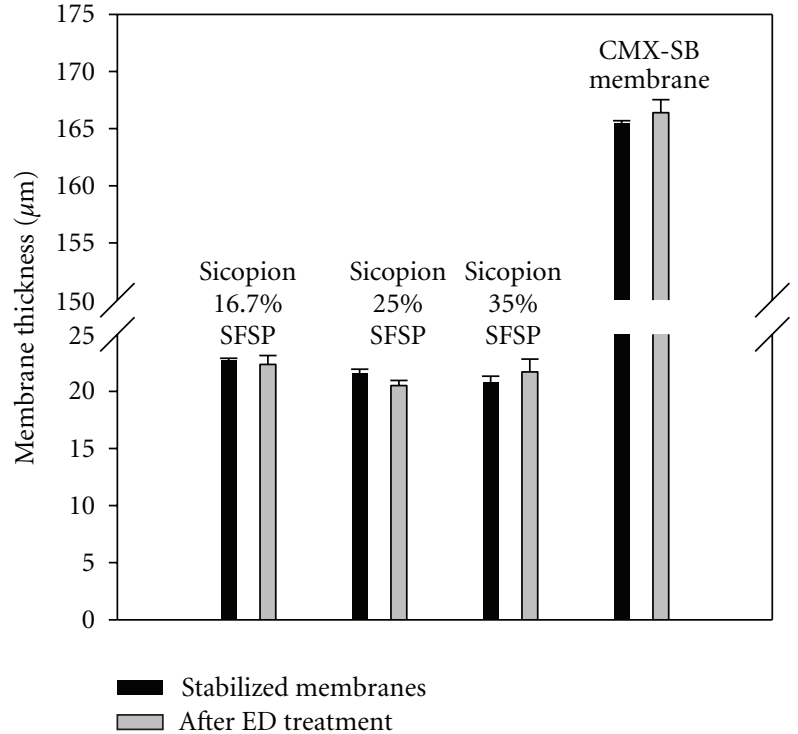

FIgure 3: Thickness of conditioned and used (24h after the ED procedure) Sicopion and CMX-SB membranes.

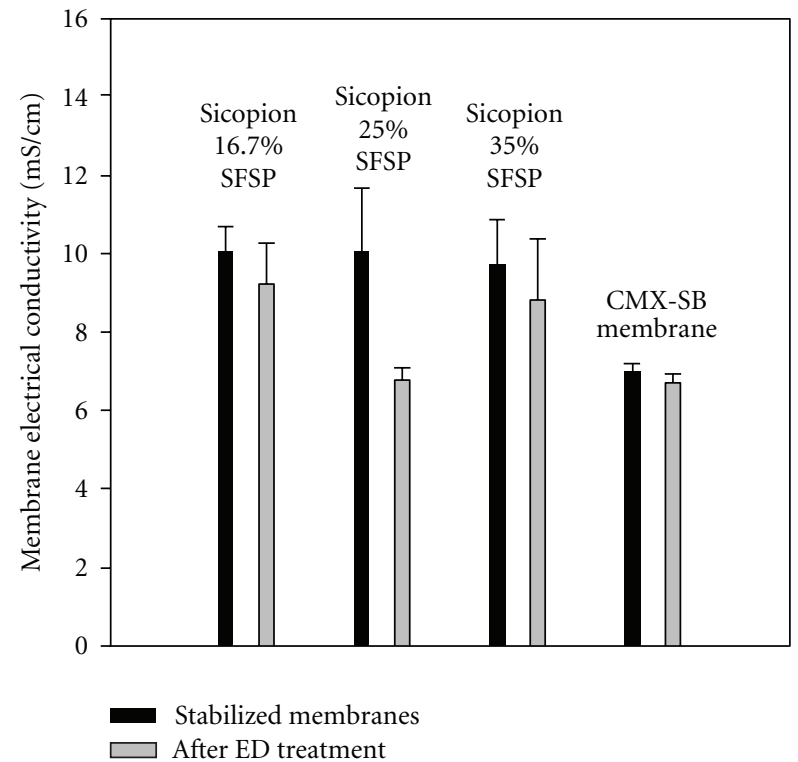

FIGURE 4: Electrical conductivity of conditioned and used $(24 \mathrm{~h}$ after the ED procedure) Sicopion and CMX-SB membranes.

3.1.3. Membrane Ion-Exchange Capacity. From the results obtained, it appeared that the IEC decreased as a higher amount of SFSP was used to prepare the Sicopion membranes (Table 1). CMX-SB membranes had an IEC within the range of Sicopion membranes with a 16.7 and $25.0 \%$ SFSP, so membranes were similar from this point of view. Sicopion membrane with 35\% SFSP presented a lower IEC than the CMX-SB membrane. The IEC of a membrane represents the amount of active ion-exchange sites present in the membrane material $[5,10]$ and constitutes an ionicquality characteristic of the latter. For conditioned Sicopion

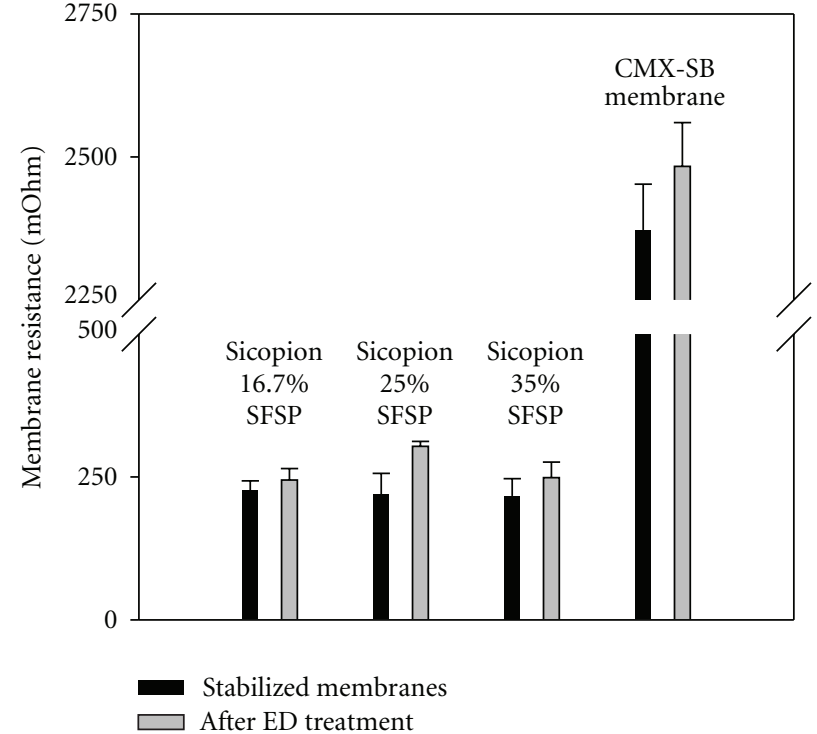

FIGURE 5: Electrical resistance of conditioned and used (24 h after the ED procedure) Sicopion and CMX-SB membranes.

membranes, their IEC was directly proportional to their SPEEK content, suggesting a functionality loss at the SFSP ion-exchange sites. IEC analysis was not performed after the ED procedure due to the limited amount of treated membrane available.

3.1.4. Water Content. Water content of Sicopion membranes varied according to their SFSP level and was, for all levels, higher than CMX-SB water content (Table 1). Sicopion membranes prepared with higher amounts of SFSP showed higher water content of the conditioned membrane (Table 1). Although silica particles have water absorption properties [1], it is possible that their functionality loss would simply translate into higher water content within the membrane structure. If IEC values obtained are pondered according to the respective water content of each membrane to obtain a wet membrane IEC value (i.e., which better reflects the real IEC of the membrane in a working ED stack) (Table 1), it is to remark that membranes still follow the trends as described earlier in the IEC section, showing that conditioned Sicopion membranes maintain their ionexchange capacity after membrane hydration. This particular property is especially important in fuel-cell applications to avoid membrane dehydration at high temperatures $[1,3$, 11]. In food applications, dehydration has been reported to be a factor in membrane integrity alterations, such as irreversible deformation and ionic passivation [2-4], so effective water retention of membrane would reduce the risk of a membrane-fouling formation.

3.1.5. Dimensional Stability. Results for dry-to-wet stability for Sicopion membranes (Table 2) demonstrated that a minimal change in their dimensions occurs when hydration occurs. This dry-to-wet dimensional stability of Sicopion 
TABLE 1: Membrane ion-exchange capacity (IEC) ( $\left.\mathrm{mEq} / \mathrm{g}_{\text {dry membrane }}\right)$, water content (\% of water on wet membrane basis), and IEC on wet membrane basis $\left(\mathrm{mEq} / \mathrm{g}_{\text {wet membrane }}\right)$.

\begin{tabular}{lccc}
\hline Membrane & IEC $\left(\right.$ dry basis, $\left.\mathrm{mEq} / \mathrm{g}_{\text {dry }}\right)$ & Water content $(\%)$ & IEC $\left(\right.$ wet basis, $\left.\mathrm{mEq} / \mathrm{g}_{\text {wet }}\right)$ \\
\hline Sicopion $16.7 \%$ SFSP & $1.394 \pm 0.000$ & $31.0 \pm 0.6$ & 0.960 \\
Sicopion $25.0 \%$ SFSP & $1.170 \pm 0.000$ & $33.5 \pm 0.3$ & 0.778 \\
Sicopion 35.0\% SFSP & $1.074 \pm 0.000$ & $37.6 \pm 2.4$ & 0.667 \\
CMX-SB & $1.231 \pm 0.023$ & $27.6 \pm 1.0$ & 0.891 \\
\hline
\end{tabular}

TABle 2: Dimensional variation coefficients (in the $X$ and $Y$ dimensions) from a dry-to-wet membrane $\left(\mathrm{Cs}_{x}, \mathrm{Cs}_{y}\right)$, after an acid bath $\left(\mathrm{Ca}_{x}\right.$, $\left.\mathrm{Ca}_{y}\right)$ and after an alkaline bath $\left(\mathrm{Cb}_{x}, \mathrm{Cb}_{y}\right)$.

\begin{tabular}{lccccccc}
\hline $\begin{array}{l}\text { CEM membrane } \\
\text { (of diluate compartment) }\end{array}$ & \multicolumn{2}{c}{ Dry to wet } & \multicolumn{2}{c}{ Acid bath } & \multicolumn{2}{c}{ Alkaline bath } \\
\hline Sicopion 16.7 \% SFSP & $0.0018 \pm 0.0016$ & $0.0000 \pm 0.0000$ & $0.0031 \pm 0.0008$ & $0.0018 \pm 0.0022$ & $0.0031 \pm 0.0008$ & $0.0018 \pm 0.0022$ \\
Sicopion 25.0 \% SFSP & $0.0000 \pm 0.0000$ & $0.0000 \pm 0.0000$ & $0.0031 \pm 0.0008$ & $0.0007 \pm 0.0014$ & $0.0038 \pm 0.0013$ & $0.0007 \pm 0.0014$ \\
Sicopion 35.0 \% SFSP & $0.0009 \pm 0.0016$ & $0.0000 \pm 0.0000$ & $0.0014 \pm 0.0016$ & $0.0007 \pm 0.0014$ & $0.0014 \pm 0.0016$ & $0.0007 \pm 0.0014$ \\
CMX-SB & n/a & n/a & $0.0029 \pm 0.0005$ & $0.0023 \pm 0.0027$ & $0.0029 \pm 0.0005$ & $0.0013 \pm 0.0027$ \\
\hline
\end{tabular}

membranes would allow a dry ED-stack assembly conditions. In contrast to commercially available membranes, such as CMX-SB, Sicopion membranes do not require wet environment for storage or installation procedures and are available in dry sheets or rolls from the manufacturer. As to their stability in acidic/alkaline media (Table 2), it was shown that all membranes had similar variation coefficients, although Sicopion membrane with 35\% SFSP seemed to be slightly more dimensionally stable that the other Sicopion membranes. It is possible to suggest, from these results, that Sicopion membrane would be dimensionally stable in acidic and alkaline media, which would constitute an advantage for cleaning-in-place (CIP) procedures.

3.1.6. Optical Microscopy. Sicopion membranes presented a granular aspect (Figure 6), showing the sites where silica particles were embedded in the SPEEK backbone. Higher SFSP levels produced less smooth surfaces, causing the membrane to seem darker (Figure 6). Also, when compared to their respective control membranes, those used for the demineralization process appeared to be slightly darker, enhancing their texture. This darkening, given by mineral traces that remain in the membrane, is normal after an ED treatment and does not necessarily imply a fouling formation, as observed in previous work on ED membrane fouling [4]. CMX-SB membranes presented the same visual texture darkening (Figure 6) and did not present any visible fouling deposits. At the same time, the different structure of both types of membranes, given their different nature and manufacture characteristics, could be observed.

3.1.7. Scanning Electron Microscopy and X-Ray EDS. SEM showed a smooth membrane surface with no signs of fouling deposits (Figure 7). On the other hand, hollow spaces were found all over the Sicopion membranes. Such cavities would correspond to the expected location of the SFSP embedded in the SPEEK matrix. This is supported by the corresponding cavity size $(\approx 5 \mu \mathrm{m})$ (Figure 8 ), corresponding to the reported average size of the SFSP used for membrane manufacture.
Table 3: Ash content (in dry basis \%) of unused (after the stabilization procedure) and used (after the demineralization procedure) CEM.

\begin{tabular}{lcc}
\hline Membrane & Unused $(\%$ ash $)$ & After ED $(\%$ ash $)$ \\
\hline Sicopion $16.7 \%$ SFSP & $13.9 \pm 1.2$ & $13.2 \pm 0.4$ \\
Sicopion $25.0 \%$ SFSP & $11.5 \pm 0.8$ & $13.2 \pm 2.2$ \\
Sicopion 35.0\% SFSP & $13.4 \pm 1.3$ & $13.7 \pm 0.8$ \\
CMX-SB & $6.9 \pm 0.5$ & $7.8 \pm 0.5$ \\
\hline
\end{tabular}

This phenomenon was the case for all Sicopion membranes (Figure 7), whose SFSP would have leached out during the alkaline wash of the conditioning procedure. The absence of the SFSP was supported by elemental analysis of the surface, where only traces of silicon were detected (Figure 9). This would explain the results found for the IEC, where no ionexchange contribution of the SFSP was observed and for the higher water content of the membranes, by replacing the space once occupied by the SFSP.

3.1.8. Membrane Ash Determination and Analysis. Total membrane ash determination confirmed the different nature of Sicopion membranes with respect to the CMX-SB membrane. Unused Sicopion membranes presented a twofold amount of ash with respect to CMX-SB membranes (Table 3), meaning that Sicopion SPEEK contains a higher amount of inorganic material than the material used in CMX-SB membranes. No differences were found among the ash contents of Sicopion membranes, supporting the fact that SFSP were removed during the conditioning procedure and that the SPEEK backbone remaining had the same composition for all membranes. When ash content of unused membranes was compared via Students $t$-tests to the respective ash content of the membrane after ED (Table 3), no differences were found for any membrane, confirming that no fouling took place during the ED procedure. Finally, the Sicopion membrane ash analysis confirmed the loss of the SFSP as shown by SEM and X-ray EDS mapping. As 


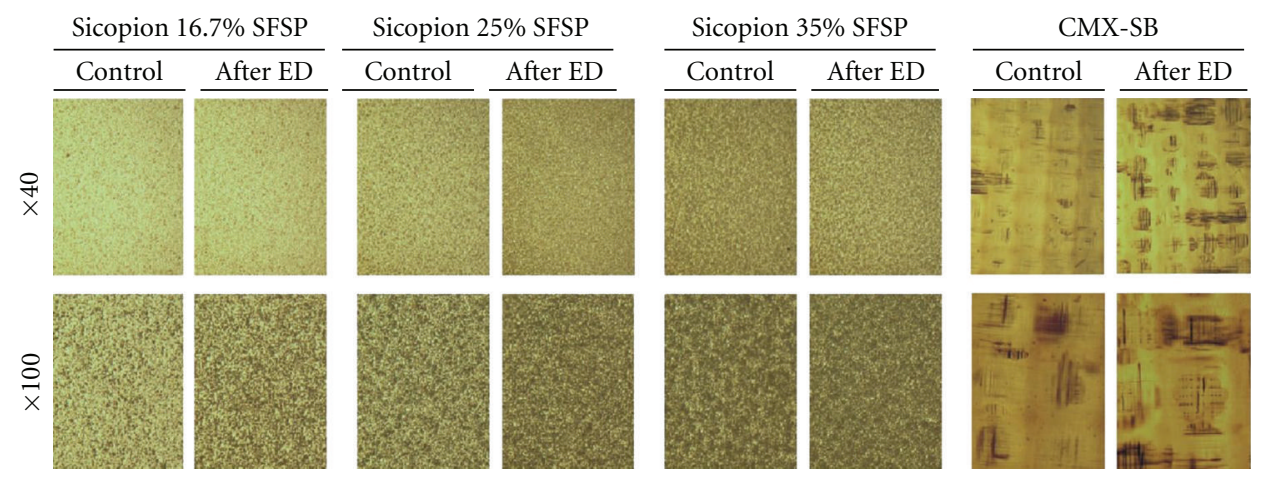

FIgURE 6: Optical microscope images of unused (control) and used (after ED) CEM at $\times 40$ and $\times 100$ magnifications.
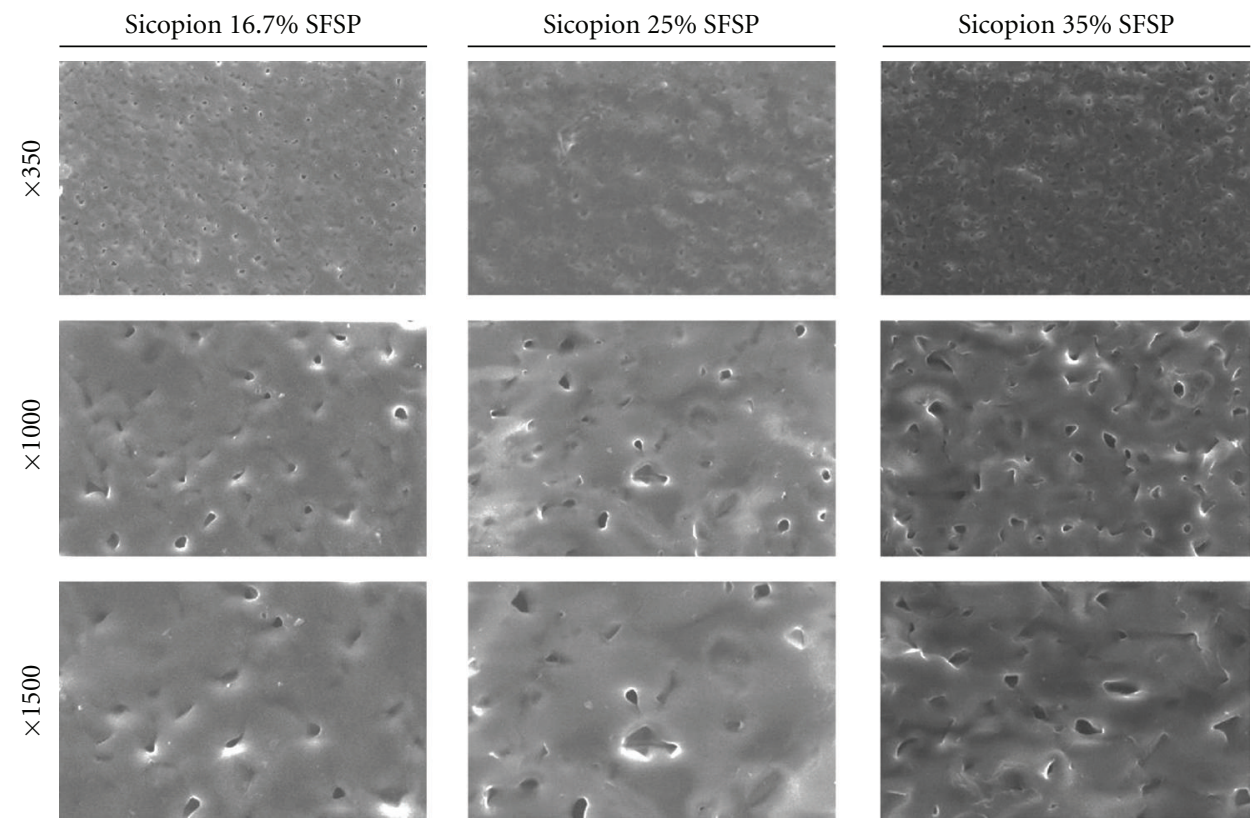

FiguRE 7: Scanning electron micrographs (SEMs) of Sicopion membranes.

expected, only traces of silicon $(<0.5 \mathrm{mg} / \mathrm{g}$ dry membrane) were detected by ICP analysis.

\subsection{Electrodialytic Parameters and Ion Migration}

3.2.1. $p H$ Variation of the Diluate and Concentrate Solutions. The $\mathrm{pH}_{\text {(diluate) }}$ varied according to the CEM membrane defining the diluate compartment (Figure 10). According to the analysis of variance and a Tukey's test, all Sicopion membranes had a significantly higher effect $(P<0.001)$ on the total $\mathrm{pH}$ variation in the diluate after a 100 -minute demineralization procedure, in contrast to CMX-SB membranes. The same case applied for the total $\mathrm{pH}$ variation of the concentrate solution $(P<0.001)$. In general, $\mathrm{pH}$ changes in the diluate were due to a more or less important leakage of $\mathrm{OH}^{-}$through the CMX or Sicopion membrane from the concentrate, leading to the $\mathrm{OH}^{-}$enrichment of the diluate. These mechanisms had a considerably more pronounced effect when Sicopion membranes were used (Figure 10), but $\mathrm{OH}^{-}$leakage has also reported to occur, in lower quantities,

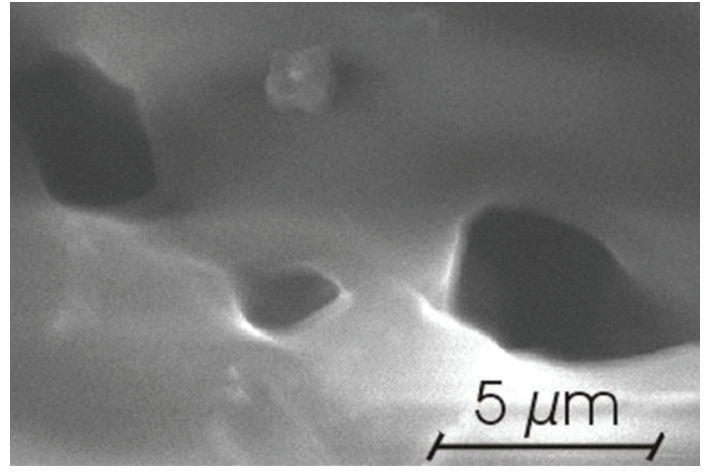

FIGURE 8: SEM of a cavity found on a Sicopion 35\% SFSP membrane.

in CMX membranes $[12,13]$. However, given the high concentration of $\mathrm{OH}^{-}$ions present in the concentrate solution, for a same amount of $\mathrm{OH}^{-}$migrating, the $\mathrm{pH}$ variation of the concentrate was much lower than that of the diluate. 


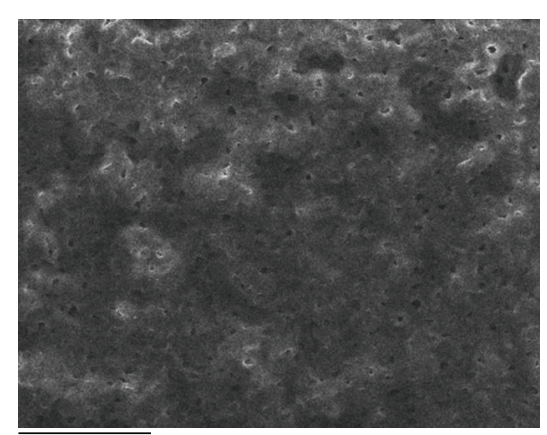

\begin{tabular}{c|c}
\hline Element & Atomic (\%) \\
$\mathrm{P}$ & 0.00 \\
$\mathrm{~K}$ & 0.00 \\
$\mathrm{Cl}$ & 0.01 \\
$\mathrm{Ca}$ & 0.01 \\
$\mathrm{Si}$ & 0.04 \\
$\mathrm{~S}$ & 1.70 \\
$\mathrm{Na}$ & 2.13 \\
$\mathrm{O}$ & 26.31 \\
$\mathrm{C}$ & 69.84 \\
\hline
\end{tabular}

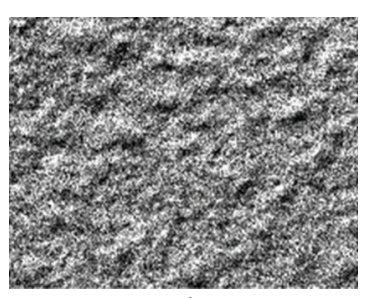

Carbon

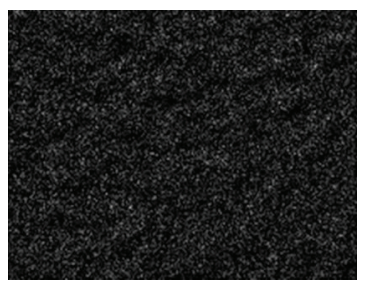

Sodium

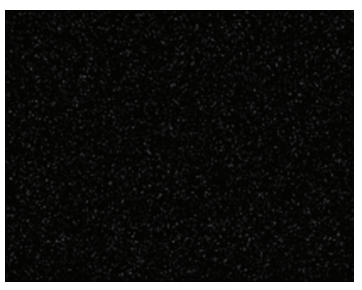

Phosphorus

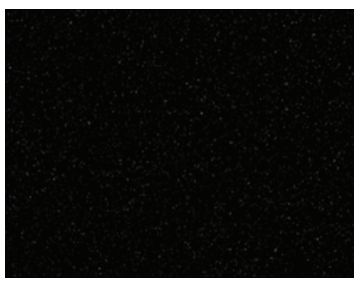

Potassium

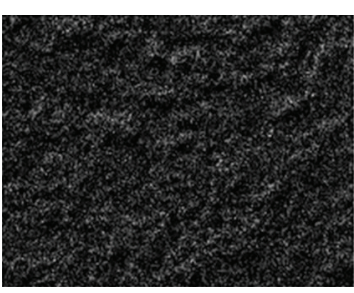

Oxygen

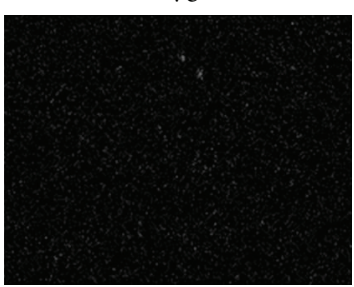

Silicon

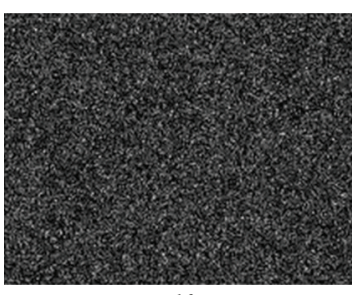

Sulfur

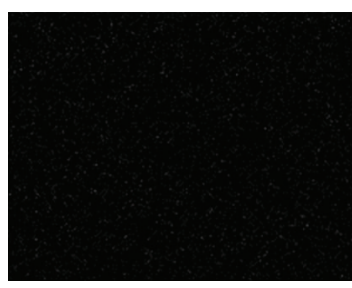

Calcium

FIGURE 9: X-ray EDS mapping and relative atomic composition for a Sicopion 35\% SFSP membrane. Bar under SEM is $100 \mu \mathrm{m}$.

Furthermore, a tendency of the $\mathrm{pH}$ values reaching a stabilization plateau could be observed (Figure 10). This would be due to the fact that, as $\mathrm{OH}^{-}$ions enriched the diluate, a fraction of them could continue their path towards the anode and traverse the AEM membrane on the other side (i.e., opposite to the defining CEM) of the diluate compartment. This way, $\mathrm{OH}^{-}$would have migrated over and over, until the $\mathrm{pH}$ difference between the concentrate and the diluate solutions had begun to equilibrate in $\mathrm{OH}^{-}$concentrations.

During the demineralization process, an $\mathrm{OH}^{-}$leakage (i.e., $\mathrm{OH}^{-}$through the cation-exchange membrane) stands as the most probable cause for such $\mathrm{pH}$ variations. This hypothesis is supported by the high water content of the Sicopion membranes, given the loss of SFSP. The hydration level of a membrane can influence its microstructure and mechanical properties [11]. Hence, water present in the membranes would act as a medium through which migrating cations could create a backflow pathway for $\mathrm{OH}^{-}$attracted towards the anode. This phenomenon would constitute the counterpart of $\mathrm{H}^{+}$leakage through the AEM similar to the Grøtthus mechanism (also termed proton hopping or structural diffusion mechanism) [14]. This proton hopping
(Figure 11; AEM) is due to the presence of proton acceptors (e.g., water molecules and acidic species contained in the feed solution within the AEM) [15]. Such proton acceptors may allow a certain coion $\left(\mathrm{H}^{+}\right.$in the case of AEM) backflow, according to the electrostatic attraction towards the cathode. As more water is present in the membrane, it is easier for a relatively large ion $\left(\mathrm{OH}^{-}\right.$in contrast to $\left.\mathrm{H}^{+}\right)$ to follow the same backflow pattern in CEM (Figure 11; CEM), using counterions traversing the membrane as a mobile ion-exchange site, to increase its own leakage through the CEM, as suggested by Piela and Wrona [16] for Nafion membranes. This was probably the case of Sicopion membranes. Furthermore, membrane thickness could have also had an effect on this backflow, by promoting a diffusion of $\mathrm{OH}^{-}$by simple concentration gradient, enhanced by the microporous structure left by the SFSP leaching. It must be mentioned that the ultrathin properties of such membranes are indeed thought according to fuel cell application, where miniaturization constitutes an important advantage, which is not necessarily the case in ED applications like bulk solution demineralization. Hence, membrane thickness, at least for ED applications, could be increased to reduce $\mathrm{OH}^{-}$ 


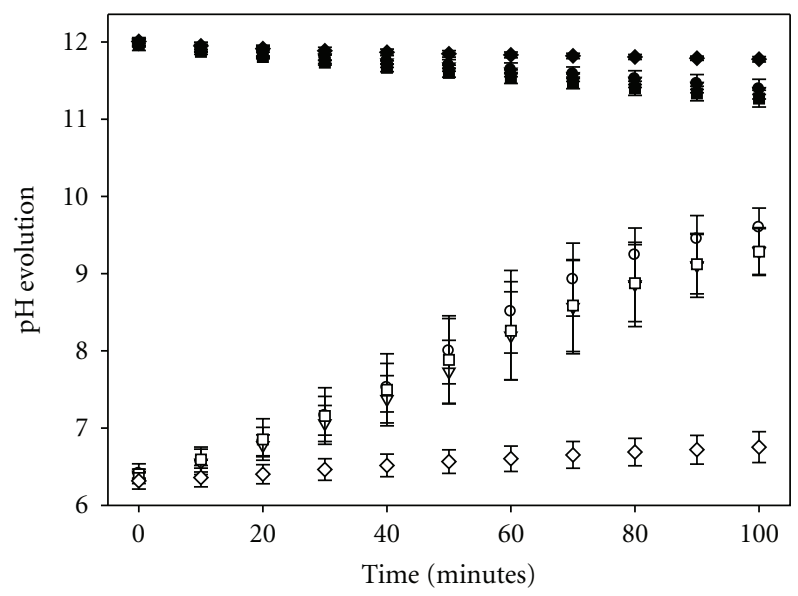

- Sicopion $16.7 \%$ SFSP - Sicopion 35\% SFSP

FIGURE 10: Evolution of $\mathrm{pH}$ in the concentrate and diluate solutions (solid and empty symbols, resp.) during the 100-minute demineralization procedure. Membranes specified in the legend indicate the CEM defining the diluate compartment.

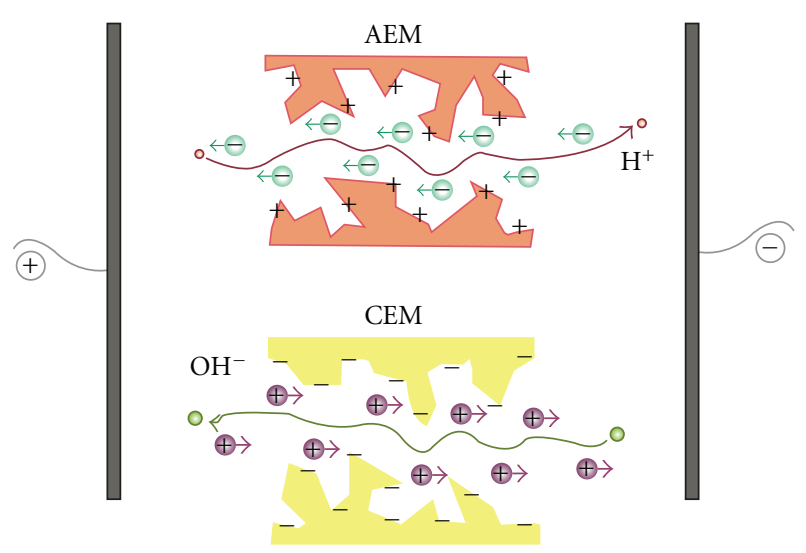

FIGURE 11: Schematic representation (offscale) of $\mathrm{H}^{+}$traversing an anion-exchange membrane (AEM) and the proposed counterpart for $\mathrm{OH}^{-}$hopping through mobile counterions in the cationexchange membrane (CEM) in a working AFNOR-conditioned Sicopion ED stack.

migration, apparently without any drawbacks on membrane performance.

It is to remark that, at least for the ED conditions used in this work, a diluate basification implied a high $\mathrm{OH}^{-}$migration through the CEM via the proposed backflow mechanism. This indicates that $\mathrm{OH}^{-}$diffusion, eased by the highly hydrated membranes and the low thickness value of the membranes, could have facilitated the mentioned phenomenon. Hence, a concentrate with a neutral $\mathrm{pH}$ would minimize $\mathrm{OH}^{-}$backflow into the diluate. In the present study, an alkaline $\mathrm{pH}$ had been chosen in order to prevent the formation of a protein fouling on the AEM defining the diluate compartment according to previous works [7].

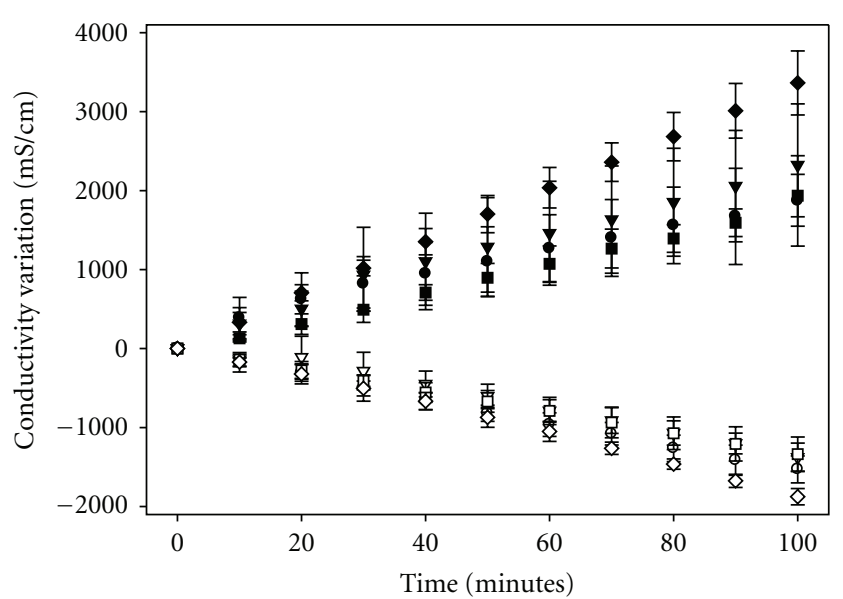

$\begin{array}{ll}\text { - Sicopion } 16.7 \% \text { SFSP } & \text { - Sicopion 35\% SFSP } \\ \text { - Sicopion 25\% SFSP } & \text { - CMX-SB membrane }\end{array}$

FIGURE 12: Conductivity evolution of the concentrate and diluate solutions (solid and empty symbols, resp.) during the 100-minute demineralization procedure. Membranes specified in the legend indicate the CEM defining the diluate compartment.

3.2.2. Conductivity Variation of the Diluate and Concentrate Solutions. Conductivity values for the diluate solution were followed to indirectly describe the demineralization progress. As expected, the conductivity increase was higher than its respective decrease in the diluate solutions because the concentrate solution is also enriched by minerals migrating from the electrode rinsing solution. Conductivity values for the diluate solution showed that demineralization rates, calculated as the variation between the initial and the final conductivity readings, were similar for all Sicopion membranes (35.94 $\pm 3.53 \%$, all membranes averaged). CMX-SB membranes, on the other hand, appeared to attain a higher demineralization rates $(45.54 \pm 2.79 \%)$, which was also confirmed by the faster conductivity increase of the concentrate solution (Figure 12). Although these demineralization rates are a good indicator of the overall process, they must be carefully interpreted, since $\mathrm{OH}^{-}$influences the conductivity values [17]. Further analysis, such as cation migration, should be compared to conductivity changes in order to determine whether the demineralization rates reflected an accurate mineral depletion and not a combination of the latter with high $\mathrm{pH}$ variation (i.e., high $\mathrm{OH}^{-}$variations).

3.2.3. Cation Migration. Cation migration evolution $\left(\mathrm{K}^{+}\right.$, $\mathrm{Na}^{+}$, and $\mathrm{Ca}^{+2}$ ) showed similar tendencies for all Sicopion membranes and confirmed the results obtained by solutionconductivity measurements. In all cases, a higher demineralization level of the diluate was found for CMX-SB membranes, with respect to Sicopion membranes (Figure 13), but equivalent mineralization levels of the concentrate streams for all membranes (Figure 13).

If cation demineralization is analyzed from the migrated charge perspective by calculating the equivalents of migrated mass, it is found that, once again, no significant differences are found between Sicopion membranes (Table 4). However, 


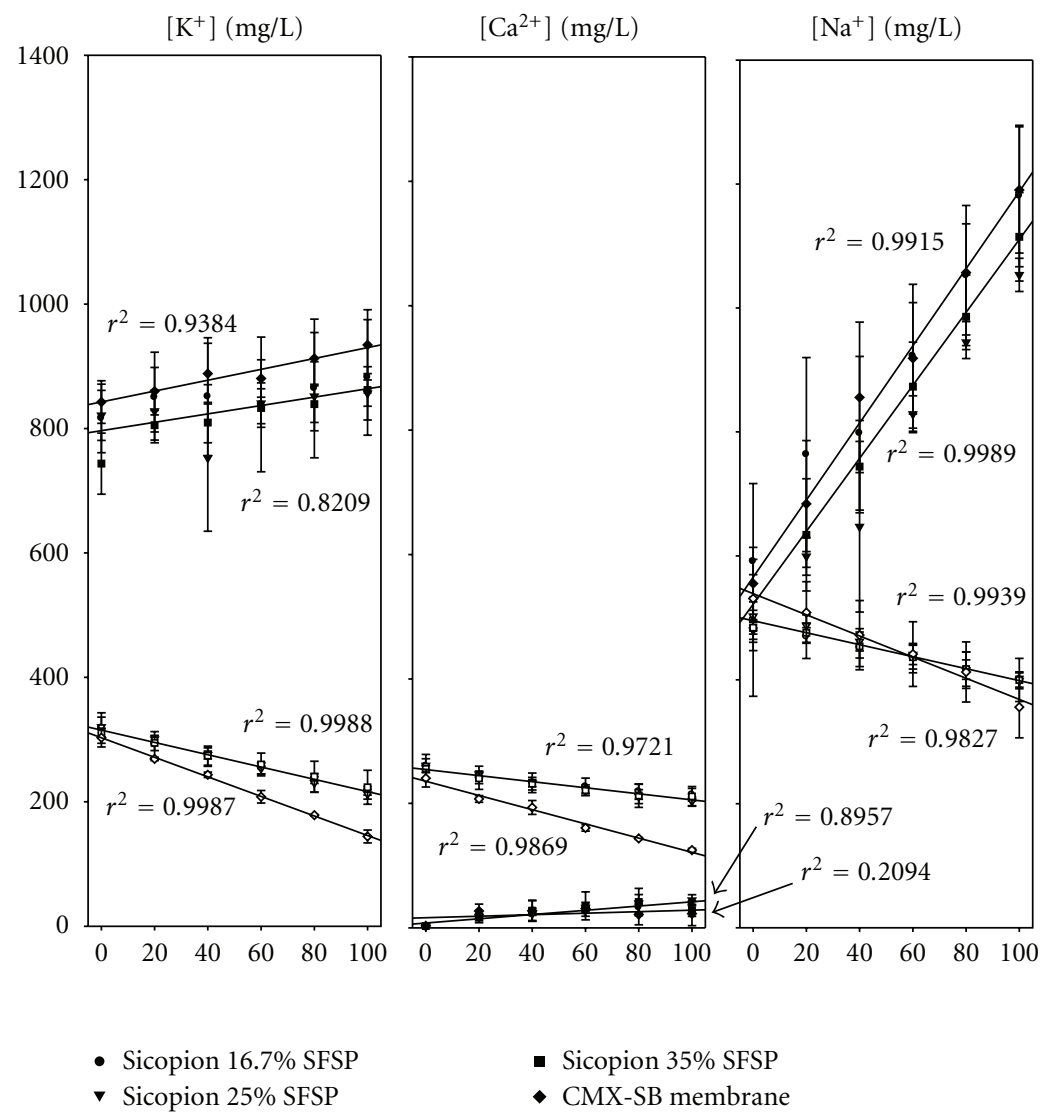

FIGURE 13: Cation concentration evolution in concentrate and diluate solutions (solid and empty symbols, resp.) treated by ED with CMXSB or Sicopion membranes. Regressions are, according to the legend, for CMX-SB membranes and for all 3 Sicopion membranes.

TABle 4: Total demineralization rates of the diluate solution in potassium, calcium, sodium, and total cations after 100-minute treatment, in milligrams per liter $(\mathrm{mg} / \mathrm{L})$ and milliequivalents per liter $(\mathrm{mEq} / \mathrm{L})$.

\begin{tabular}{|c|c|c|c|c|c|c|c|}
\hline \multirow{2}{*}{$\begin{array}{l}\text { CEM membrane } \\
\text { (of diluate compartment) }\end{array}$} & \multicolumn{2}{|c|}{ K } & \multicolumn{2}{|c|}{$\mathrm{Ca}$} & \multicolumn{2}{|c|}{$\mathrm{Na}$} & \multirow{2}{*}{$\begin{array}{c}\text { Total } \\
\mathrm{mEq} / \mathrm{L}\end{array}$} \\
\hline & $\mathrm{mg} / \mathrm{L}$ & $\mathrm{mEq} / \mathrm{L}$ & $\mathrm{mg} / \mathrm{L}$ & $\mathrm{mEq} / \mathrm{L}$ & $\mathrm{mg} / \mathrm{L}$ & $\mathrm{mEq} / \mathrm{L}$ & \\
\hline Sicopion $16.7 \%$ SFSP & $100.85 \pm 26.76$ & $2.58 \pm 0.68$ & $45.92 \pm 14.17$ & $2.29 \pm 0.71$ & $96.38 \pm 27.28$ & $4.19 \pm 1.19$ & $9.06 \pm 2.55$ \\
\hline Sicopion $25.0 \%$ SFSP & $108.00 \pm 21.14$ & $2.76 \pm 0.54$ & $57.48 \pm 15.99$ & $2.87 \pm 0.80$ & $104.23 \pm 25.46$ & $4.53 \pm 1.11$ & $10.17 \pm 2.42$ \\
\hline Sicopion $35.0 \%$ SFSP & $87.42 \pm 22.85$ & $2.24 \pm 0.58$ & $44.03 \pm 16.23$ & $2.20 \pm 0.81$ & $84.47 \pm 25.41$ & $3.67 \pm 1.11$ & $8.11 \pm 2.45$ \\
\hline CMX-SB & $158.66 \pm 16.13$ & $4.06 \pm 0.41$ & $115.40 \pm 15.36$ & $5.76 \pm 0.77$ & $175.20 \pm 16.49$ & $7.62 \pm 0.72$ & $17.44 \pm 1.79$ \\
\hline
\end{tabular}

and in contrast to cation concentration evolutions, mineralization rates of the concentrate, expressed as net migrated milliequivalents, turned out to be equivalent for CMX-SB and Sicopion membranes (Table 5). On the other hand, demineralization rates of the diluate solution did show an important difference between the CMX-SB membrane and the Sicopion ones. Since the concentrate mineralization levels were equivalent and the demineralization rates were higher for the ED procedures where a CMX-SB was used, the balancing species mineralizing the concentrate would have come from the electrolyte solution. However, $\mathrm{Na}^{+}$concentrations are those with the higher migration rate towards the concentrate, confounding ions coming from the diluate and from the electrolyte solution into the concentrate compartment. According to the initial concentration of such ions in the diluate, it is possible to say that they demonstrated to be the predominant cations for current flow. At the same time, the higher cation levels $\left(\mathrm{K}^{+}, \mathrm{Na}^{+}, \mathrm{Ca}^{+2}\right)$ present in the diluates demineralized with a Sicopion membrane would confirm what was explained in the $\mathrm{pH}$ evolution section of this paper. Cations migration was disfavoured by the enrichment in $\mathrm{OH}^{-}$of the diluate, maintaining the electroneutrality of the solution as it compensated for the anions migrating through the AEM.

3.2.4. System Resistance. System resistance evolution was similar for all stacks equipped with Sicopion membranes (Figure 14). Towards the end of the demineralization procedures, resistance increased at a higher rate for CMX-SB membranes due to the lower conductivity of the diluate 
TABLE 5: Total mineralization rates of the concentrate solution in potassium, calcium, sodium, and total cations after 100-minute treatment, in milligrams per liter $(\mathrm{mg} / \mathrm{L})$ and milliequivalents per liter $(\mathrm{mEq} / \mathrm{L})$.

\begin{tabular}{lccccccc}
\hline $\begin{array}{l}\text { CEM membrane } \\
\text { (of diluate compartment) }\end{array}$ & \multicolumn{2}{c}{$\mathrm{Kg} / \mathrm{L}$} & $\mathrm{mEq} / \mathrm{L}$ & $\mathrm{mg} / \mathrm{L}$ & $\mathrm{mEq} / \mathrm{L}$ & $\mathrm{mg} / \mathrm{L}$ & $\begin{array}{c}\mathrm{Na} \\
\mathrm{mEq} / \mathrm{L}\end{array}$ \\
\hline Sicopion 16.7\% SFSP & $65.98 \pm 37.96$ & $1.69 \pm 0.97$ & $34.40 \pm 5.08$ & $1.72 \pm 0.25$ & $589.74 \pm 53.05$ & $25.65 \pm 2.31$ & $29.06 \pm 3.52$ \\
Sicopion 25.0\% SFSP & $35.47 \pm 8.09$ & $0.91 \pm 0.21$ & $41.87 \pm 8.48$ & $2.09 \pm 0.42$ & $573.60 \pm 14.27$ & $24.95 \pm 0.62$ & $27.95 \pm 1.09$ \\
Sicopion 35.0\% SFSP & $118.44 \pm 71.45$ & $3.03 \pm 1.83$ & $25.25 \pm 10.90$ & $1.26 \pm 0.54$ & $630.89 \pm 49.81$ & $27.44 \pm 2.17$ & $31.73 \pm 4.33$ \\
CMX-SB & $91.94 \pm 26.72$ & $2.35 \pm 0.68$ & $19.67 \pm 19.23$ & $0.98 \pm 0.96$ & $634.99 \pm 43.82$ & $27.62 \pm 1.91$ & $30.95 \pm 1.60$ \\
\hline
\end{tabular}

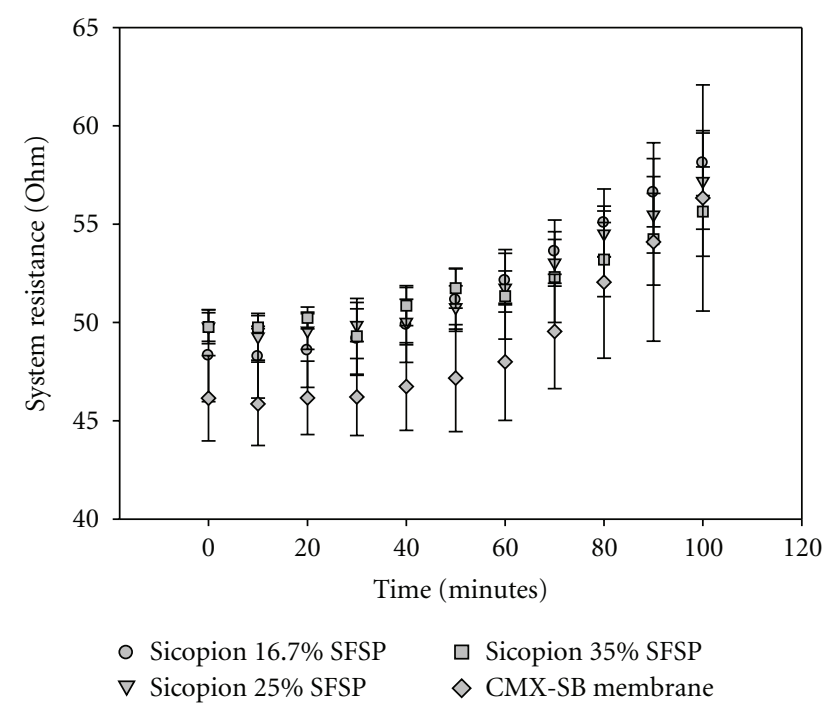

FIGURE 14: Resistance evolution of the ED stacks during the 100minute demineralization procedure. Membranes specified in the legend indicate the CEM defining the diluate compartment.

solution, given by its higher demineralization level with respect to Sicopion membranes, as previously explained for conductivity variation. In addition, the stack resistance was found to be, in general, slightly higher $(\approx 5 \Omega)$ when equipped with Sicopion membranes, with respect to the stack with CMX-SB (Figure 14). This could be explained by the $\mathrm{OH}^{-}$traversing the CEM, partially hindering the current flow, since it was found that Sicopion membranes actually had a lower electrical resistance than CMX-SB membranes (Figure 5). This resistance difference seems normal, given the important thickness difference between the two types of membranes and to the fact that the materials they are made of have, in general, similar IEC values. Hence, the $\mathrm{OH}^{-}$ backflow could account for the global increased resistance of the system.

3.2.5. Energy Consumption. The results obtained showed a similar consumption for all membranes, Sicopion (1.47 \pm $0.03 \mathrm{Wh})$ and CMX-SB $(1.38 \pm 0.08 \mathrm{Wh})$. Although CMXSB membranes allowed a higher demineralization rate, total migration through Sicopion membranes was probably equivalent, given the high amount of $\mathrm{OH}^{-}$transported through the latter. Such backflow would have consumed a certain amount of energy, hence reducing the global demineralization rate of the diluate and increasing the energy consumption of the ED procedure.

\section{Conclusion}

In this study, it was shown that membrane conditioning actually leaches out the SFSP leaving a water-enriched microporous structure of SPEEK. Important variations were found only at the IEC level and water content of the membranes. These variations, however, did not show any significant effects on their practical electrodialytic characteristics for the demineralization conditions used in this particular work.

With respect to CMX-SB membranes, several differences were found for Sicopion membranes, but these were mainly due to the different nature of such membranes. The most important difference between both types of membranes was their $\mathrm{OH}^{-}$permeability, being considerably higher for Sicopion membranes. Membrane composition and imaging supported the $\mathrm{OH}^{-}$backflow hypothesis. The membrane cavities would contribute to higher water content of the membranes and, by creating microscopic pores, would increase the amount of $\mathrm{OH}^{-}$backflow paths, as previously discussed. Although $\mathrm{OH}^{-}$permeability of Sicopion membranes could offer a new perspective for some specific applications, like fruit juice deacidification [18], $\mathrm{OH}^{-}$leakage could be reduced by increasing the membrane thickness, reducing the backflow and diffusion of $\mathrm{OH}^{-}$. Sicopion membranes would then be an interesting option for procedures requiring relatively constant or acidic pH conditions. Indeed, according to previous studies [7], a neutral $\mathrm{pH}$ would minimize the risk of a CEM integrity alteration due to fouling during the demineralization of liquid foodstuffs containing proteins and divalent cations. In addition, the loss of SFSP during conditioning could be a way for manufacturing membranes with micro- or nanoscale pores that could be used in electrodialysis with filtration membrane. This new electromembrane technology separates bioactive molecules according to their charge (electric field as driving force) and size (molecular weight cutoff of the filtration membrane) [19]. Finally, one of the most attractive advantages of Sicopion membranes is their dry-to-hydrated dimensional stability which is of particular interest for industrial-scale ED stacks, since (as for CEM) it would allow a dry mounting process. This contrasts with the wet environment that must be maintained during the stack assembly for commercially available membranes. 


\section{Acknowledgments}

The authors wish to thank Ms. Monica Araya-Farias from the Laval University, Ms. Diane Montpetit from the Agriculture and Agri-Food Canada, Mr. Pierre-Gilles Vaillancourt from the SiM Composite, and Ms. Isabelle Montplaisir from the Laboratory of Energy Technologies (LET) for their technical assistance. The support of the Hydro-Quebec Research Institute and access given to LET is also acknowledged. The authors recognized that there is no conflict of interests concerning the quality of results obtained.

\section{References}

[1] M. St-Arnaud and P. Bebin, "Ion exchange composite material based on proton conductive silica particles dispersed in a polymer matrix," Patent, WO 03/083985 A2, 2003.

[2] W. Richard Bowen, T. A. Doneva, and H. B. Yin, "Polysulfone-Sulfonated poly(ether ether) ketone blend membranes: systematic synthesis and characterisation," Journal of Membrane Science, vol. 181, no. 2, pp. 253-263, 2001.

[3] V. Baglio, A. S. Aricò, V. Antonucci et al., "An NMR spectroscopic study of water and methanol transport properties in DMFC composite membranes: influence on the electrochemical behaviour," Journal of Power Sources, vol. 163, no. 1, pp. 52-55, 2006.

[4] E. Ayala-Bribiesca, G. Pourcelly, and L. Bazinet, "Nature identification and morphology characterization of cation-exchange membrane fouling during conventional electrodialysis," Journal of Colloid and Interface Science, vol. 300, no. 2, pp. 663-672, 2006.

[5] Association Française de Normalisation, Norme française homologuée pour les membranes polymères échangeuses d'ions NF X 45-200. France, 1995.

[6] E. Räsänen, M. Nyström, J. Sahlstein, and O. Tossavainen, "Purification and regeneration of diluted caustic and acidic washing solutions by membrane filtration," Desalination, vol. 149, no. 1-3, pp. 185-190, 2002.

[7] E. Ayala-Bribiesca, M. Araya-Farias, G. Pourcelly, and L. Bazinet, "Effect of concentrate solution $\mathrm{pH}$ and mineral composition of a whey protein diluate solution on membrane fouling formation during conventional electrodialysis," Journal of Membrane Science, vol. 280, no. 1-2, pp. 790-801, 2006.

[8] D. A. Cowan and J. H. Brown, "Effect of turbulence on limiting current in electrodialysis cells," Industrial \& Engineering Chemistry, vol. 51, no. 12, pp. 1445-1448, 1959.

[9] L. Bazinet, F. Lamarche, R. Labrecque, and D. Ippersiel, "Effect of number of bipolar membranes and temperature on the performance of bipolar membrane electroacidification," Journal of Agricultural and Food Chemistry, vol. 45, no. 10, pp. 3788-3794, 1997.

[10] L. Bazinet, D. Ippersiel, D. Montpetit, B. Mahdavi, J. Amiot, and F. Lamarche, "Effect of membrane permselectivity on the fouling of cationic membranes during skim milk electroacidification," Journal of Membrane Science, vol. 174, no. 1, pp. 97 $110,2000$.

[11] R. Jiang, H. R. Kunz, and J. M. Fenton, "Composite silica/ Nafion membranes prepared by tetraethylorthosilicate sol-gel reaction and solution casting for direct methanol fuel cells," Journal of Membrane Science, vol. 272, no. 1-2, pp. 116-124, 2006.

[12] L. Bazinet, D. Montpetit, D. Ippersiel, J. Amiot, and F. Lamarche, "Identification of skim milk electroacidification fouling: a microscopic approach," Journal of Colloid and Interface Science, vol. 237, no. 1, pp. 62-69, 2001.

[13] L. Bazinet, D. Montpetit, D. Ippersiel, B. Mahdavi, J. Amiot, and F. Lamarche, "Neutralization of hydroxide generated during skim milk electroacidification and its effect on bipolar and cationic membrane integrity," Journal of Membrane Science, vol. 216, no. 1-2, pp. 229-239, 2003.

[14] D. Seeliger, C. Hartnig, and E. Spohr, "Aqueous pore structure and proton dynamics in solvated Nafion membranes," Electrochimica Acta, vol. 50, no. 21, pp. 4234-4240, 2005.

[15] S. Roualdes, N. Kourda, J. Durand, and G. Pourcelly, "Plasmagrafted PVDF polymers as anion exchange membranes for the electrotransport of Cr(VI)," Desalination, vol. 146, no. 1-3, pp. 273-278, 2002.

[16] P. Piela and P. K. Wrona, "Some anion-transport properties of Nafion 117 from fuel cell hydrogen peroxide generation data," Journal of Power Sources, vol. 158, no. 2, pp. 1262-1269, 2006.

[17] F. L. T. Shee, P. Angers, and L. Bazinet, "Relationship between electrical conductivity and demineralization rate during electroacidification of cheddar cheese whey," Journal of Membrane Science, vol. 262, no. 1-2, pp. 100-106, 2005.

[18] E. Vera, J. Sandeaux, F. Persin, G. Pourcelly, M. Dornier, and J. Ruales, "Deacidification of clarified tropical fruit juices by electrodialysis-part I. Influence of operating conditions on the process performances," Journal of Food Engineering, vol. 78, no. 4, pp. 1427-1438, 2007.

[19] L. Bazinet and L. Firdaous, "Membrane processes and devices for separation of bioactive peptides," Recent Patents on Biotechnology, vol. 3, no. 1, pp. 61-72, 2009. 

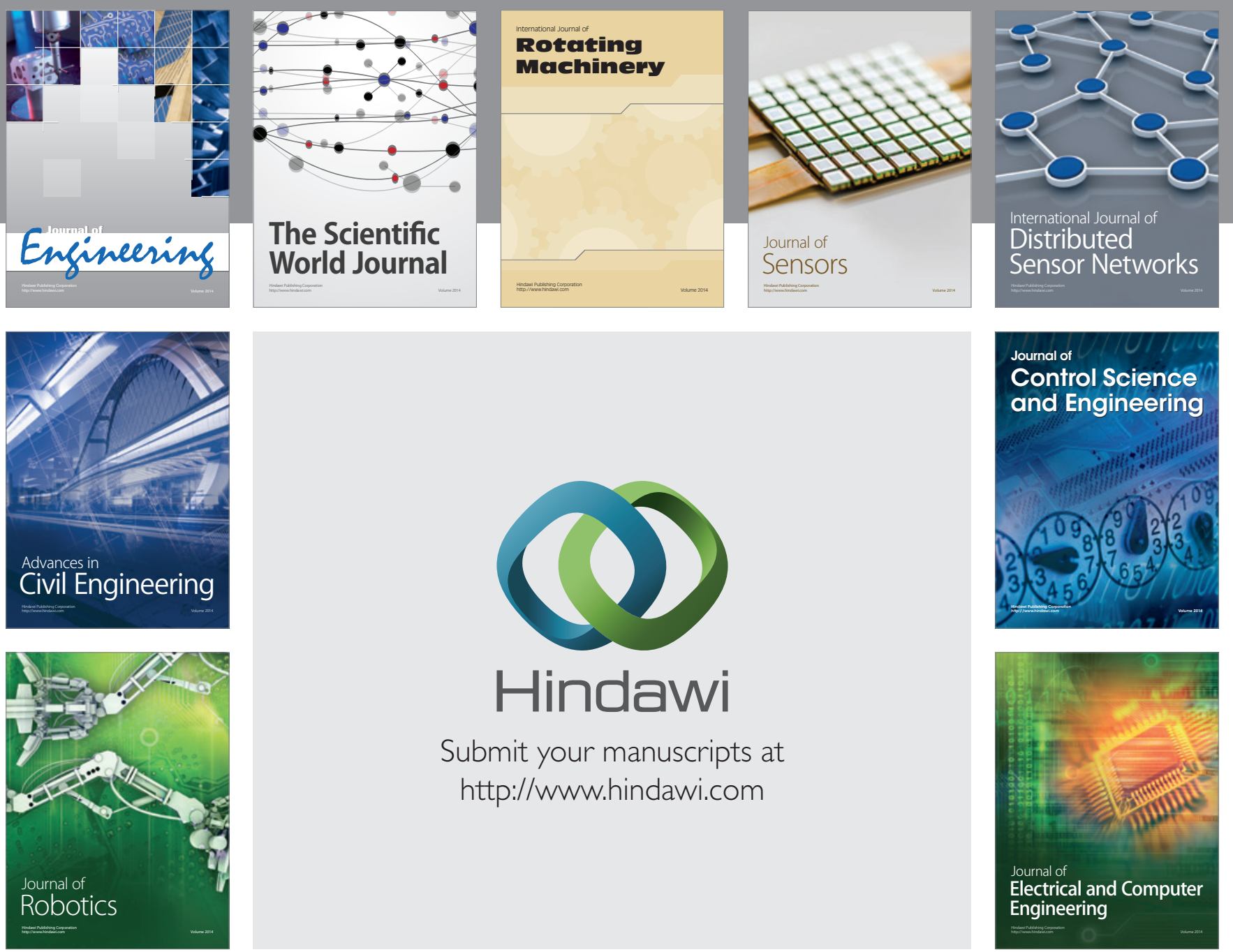

Submit your manuscripts at

http://www.hindawi.com
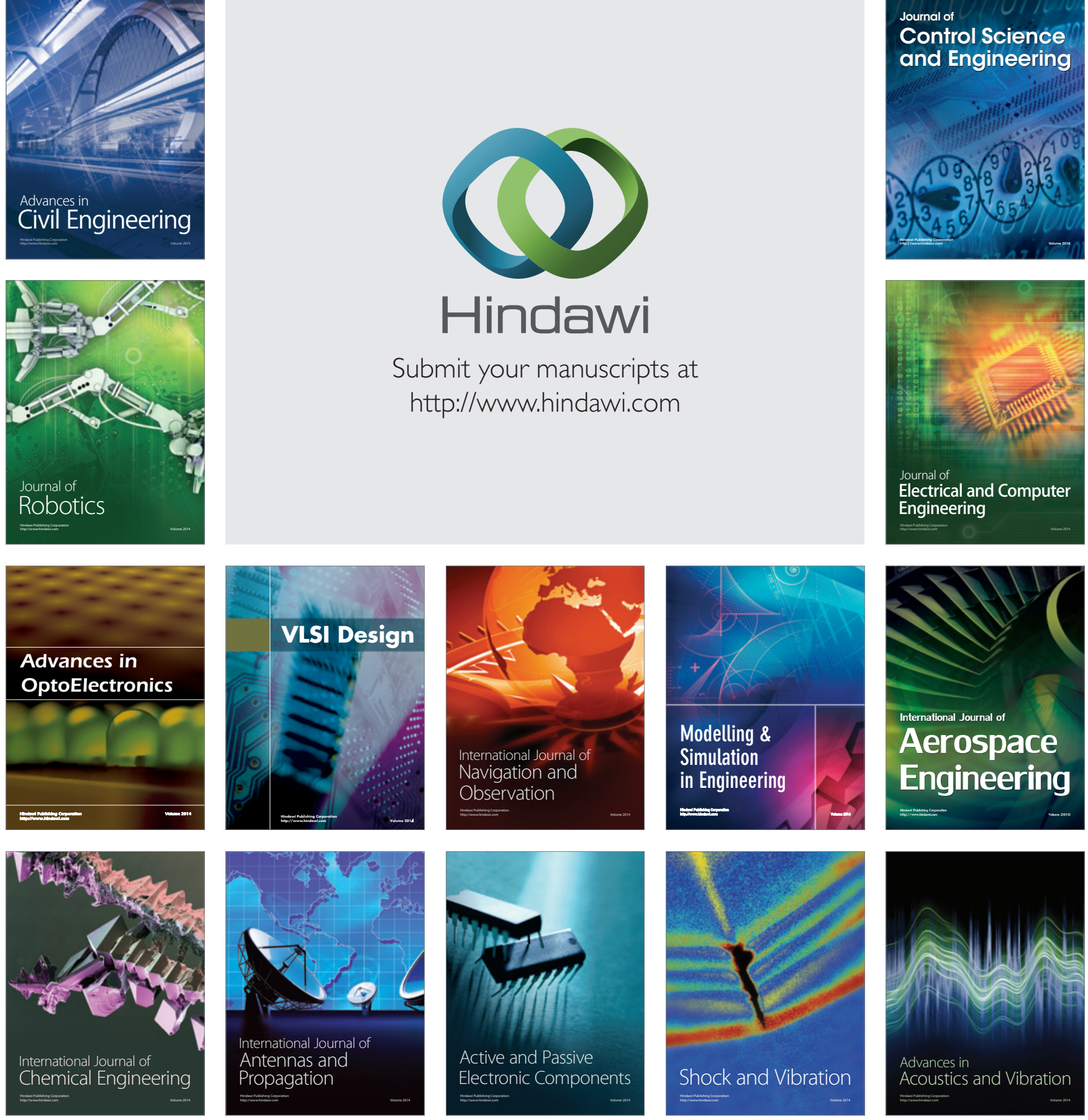